\title{
Investigating the differential effects of social networking site addiction and Internet gaming disorder on psychological health
}

\author{
HALLEY M. PONTES* \\ International Gaming Research Unit, Psychology Department, Nottingham Trent University, Nottingham, United Kingdom
}

(Received: June 25, 2017; revised manuscript received: October 2, 2017; accepted: October 22, 2017)

\begin{abstract}
Background and aims: Previous studies focused on examining the interrelationships between social networking site (SNS) addiction and Internet gaming disorder (IGD) in isolation. Moreover, little is known about the potential simultaneous differential effects of SNS addiction and IGD on psychological health. This study investigated the interplay between these two technological addictions and ascertained how they can uniquely and distinctively contribute to increasing psychiatric distress when accounting for potential effects stemming from sociodemographic and technology-related variables. Methods: A sample of 509 adolescents (53.5\% males) aged 10-18 years (mean = $13.02, S D=1.64)$ were recruited. Results: It was found that key demographic variables can play a distinct role in explaining SNS addiction and IGD. Furthermore, it was found that SNS addiction and IGD can augment the symptoms of each other, and simultaneously contribute to deterioration of overall psychological health in a similar fashion, further highlighting potentially common etiological and clinical course between these two phenomena. Finally, the detrimental effects of IGD on psychological health were found to be slightly more pronounced than those produced by SNS addiction, a finding that warrants additional scientific scrutiny. Discussion and conclusion: The implications of these results are further discussed in light of the existing evidence and debates regarding the status of technological addictions as primary and secondary disorders.
\end{abstract}

Keywords: technological addictions, behavioral addictions, Internet gaming disorder, social networking site addiction, mental health

\section{INTRODUCTION}

The latest technological advancements played a key role in changing the way individuals experience social networking sites (SNS) and video games. Although these developments enhanced users' overall experiences across both activities, they have also contributed to further blurring the dividing line between SNS use and video game play (Rikkers, Lawrence, Hafekost, \& Zubrick, 2016; Starcevic \& Aboujaoude, 2016).

Virtual social experiences and interactive processes are heavily embedded across different game genres, particularly in massively multiplayer online role-playing games (MMORPGs), where users can play in virtual social worlds. A relatively large survey of 912 MMORPG players from 45 countries found that social interactions within gaming environments form a considerable element in the enjoyment of playing as gamers can make lifelong friends and partners throughout their gaming experiences (Cole \& Griffiths, 2007). Interestingly, social media experiences in the era of Web 2.0 include popular social media games that are rising in popularity (Bright, Kleiser, \& Grau, 2015), with the latest figures from Facebook suggesting that in 2014, an average of 375 million people have played Facebook-connected games each month, and that mobile applications sent an average of 735 million referrals to games every day (Facebook, 2014).
Despite the widely reported positive and beneficial effects of both SNS and video games at many levels (e.g., cognitive functioning, well-being, etc.) (e.g., Chopik, 2016; Heo, Chun, Lee, Lee, \& Kim, 2015; Howard, Wilding, \& Guest, 2016; Stroud \& Whitbourne, 2015), there is also mounting evidence from several nationwide representative empirical studies demonstrating that SNS and video games can contribute to psychosocial impairments and behavioral dysfunction in a minority of users, including young adolescents who may use these technologies excessively and unhealthily given their current developmental stage (Andreassen, 2015; Bányai et al., 2017; Cock et al., 2014; Morioka et al., 2016; Pápay et al., 2013). More recently, Sioni, Burleson, and Bekerian (2017) conducted an empirical study in a sample of 595 MMORPG players from the United States and found that addictive video game play was positively associated with symptoms of social phobia even after controlling for the shared influence of weekly gaming hours, further illustrating that socially phobic individuals prefer online forms of social interactions

* Corresponding address: Dr. Halley M. Pontes, PhD; International Gaming Research Unit, Psychology Department, Nottingham Trent University, 50 Shakespeare Street, Nottingham NG1 4QF, United Kingdom; Phone/Fax: +44 115848 2870; E-mail: contactme@halleypontes.com 
(Lee \& Stapinski, 2012) as they provide users with the unique opportunity to satisfy their social connection needs, while simultaneously allowing them to leave social situations in which they feel uncomfortable (e.g., by logging out of the game). With regard to excessive SNS use, a recent study conducted by Xanidis and Brignell (2016) in a sample of 324 social media users found that SNS addiction was a key predictor of decreased sleep quality and increased incidence of cognitive failures. Furthermore, Xanidis and Brignell (2016) noted that SNS addiction can potentiate cognitive failures due to its negative effects on sleep quality, further illustrating the key clinical and sociological importance of research related to technological addictions in educational contexts as excessive and pathological SNS and video game use can both compromise physical and mental health in a variety of contexts and age ranges.

At the theoretical level, video game addiction [also known as Internet gaming disorder (IGD)] is a clinical condition that comprises a behavioral pattern encompassing persistent and recurrent use of video games, leading to significant impairment or distress over a period of 12 months as indicated by endorsing five (or more) of the following nine criteria: (i) preoccupation with games; (ii) withdrawal symptoms when gaming is taken away; (iii) tolerance, resulting in the need to spend increasing amounts of time engaged in games; (iv) unsuccessful attempts to control participation in games; (v) loss of interest in previous hobbies and entertainment as a result of, and with the exception of, games; (vi) continued excessive use of games despite knowledge of psychosocial problems; (vii) deceiving family members, therapists, or others regarding the amount of gaming; (viii) use of games to escape or relieve negative moods; and (ix) jeopardizing or losing a significant relationship, job, or education or career opportunity because of participation in games (American Psychiatric Association [APA], 2013). As for SNS addiction, this construct is broadly defined as "being overly concerned about SNSs, to be driven by a strong motivation to $\log$ on to or use SNSs, and to devote so much time and effort to SNSs that it impairs other social activities, studies/job, interpersonal relationships, and/or psychological health and wellbeing" (Andreassen \& Pallesen, 2014, p. 4054).

Since the initial proposal of IGD as a tentative disorder by the APA in the fifth edition of the Diagnostic and Statistical Manual of Mental Disorders (DSM-5; APA, 2013), several scholarly debates presenting distinct and conflicting views regarding the feasibility and status of IGD as an official disorder have been published (Aarseth et al., 2016; Griffiths, Van Rooij, et al., 2016; Lee, Choo, \& Lee, 2017; Petry et al., 2014, 2015; Saunders et al., 2017). Some of these concerns emerged due to the fact that the diagnostic criteria for IGD were largely derived from a combination of existing clinical criteria and unofficial conditions such as: pathological gambling, substance use disorder, and generalized Internet addiction (Kuss, Griffiths, \& Pontes, 2017). Despite the fact that IGD and SNS addictions are not officially recognized mental health disorders, the World Health Organization (2016) intensified the debate surrounding video game addiction due to its decision to include gaming disorder (GD) as a formal disorder in the next revision of the International Classification of Diseases. Another issue involved in behavioral addictions, such as SNS addiction and IGD, relates to the fact that spontaneous remission can occur in many cases. Research examining remission rates in IGD reported that spontaneous remission can occur in up to $50 \%$ of cases (e.g., Gentile et al., 2011; Scharkow, Festl, \& Quandt, 2014; Van Rooij, Schoenmakers, Vermulst, Van den Eijnden, \& Van de Mheen, 2011).

Although prevalence rates of SNS addiction and IGD can be significantly affected by factors such as methodological and conceptual issues as previously suggested (Griffiths, Király, Pontes, \& Demetrovics, 2015; Griffiths, Kuss, \& Pontes, 2016; Griffiths \& Pontes, 2015), robust studies (i.e., nationally representative studies) reported prevalence rates of SNS addiction ranging from $2.9 \%$ in the Belgian adult population (Cock et al., 2014) to $4.5 \%$ among Hungarian adolescents (Bányai et al., 2017). Even though IGD prevalence rates from robust studies found rates range from 2.5\% in Slovenian adolescents (Pontes, Macur, \& Griffiths, 2016) to 5.8\% among Dutch adolescents and adults (Lemmens \& Hendriks, 2016), other large-scale studies reported prevalence rates as low as $0.3 \%$ (Scharkow et al., 2014). Although findings on prevalence appear to be relatively consistent across robust studies, some factors may contribute to inflation of estimations. For instance, it has been found that mischievous and extreme patterns of responding can inflate estimates of prevalence rates (Przybylski, 2017). Similarly, the type of psychometric assessment utilized has been shown to contribute to overestimation of prevalence rates of rare disorders, such as IGD (Maraz, Király, \& Demetrovics, 2015).

Since the extant knowledge based on the effects of SNS and video game play on psychological health in young adolescents is arguably sparse, research on the potential differential effects of SNS addiction and IGD on psychological health is paramount since these two phenomena share a common underlying etiology with other substancerelated and behavioral addictions (Griffiths, 2015; Griffiths \& Pontes, 2015; Shaffer et al., 2004), and that increased social gaming impairs the overall quality of interpersonal relationships in adolescents by hampering emotional support (Kowert, Domahidi, Festl, \& Quandt, 2014).

\section{The current study}

Previous studies (e.g., Andreassen et al., 2016; Cock et al., 2014; Pontes \& Griffiths, 2015b; Yu, Li, \& Zhang, 2015) found that gender and age can increase vulnerability toward both SNS addiction and IGD. Therefore, since male gender has systematically been associated with IGD and female gender with SNS addiction (Andreassen et al., 2016), this study hypothesizes that gender and age will predict greater levels of SNS addiction and IGD symptoms (H1). In addition, several studies (e.g., Andreassen et al., 2013, 2016; Sussman et al., 2014) have reported positive associations between different types of technological addictions, suggesting common underlying correlates. Hence, it is hypothesized that SNS addiction and IGD will be positively associated with each other (H2). Although the relationship between SNS addiction, IGD, and mental health is complex 
and remains controversial at best (Pantic, 2014), a large body of evidence reported key correlates of technological addictions, such as depression, anxiety, and stress (e.g., Király et al., 2014; Lehenbauer-Baum et al., 2015; Ostovar et al., 2016; Pontes \& Griffiths, 2016). Thus, it is hypothesized that SNS addiction and IGD will both contribute uniquely and differentially toward increasing overall levels of psychiatric distress (H3). All of the three aforementioned hypotheses will be investigated accounting for potential effects stemming from high frequency of Internet use and video game play as time spent in these activities are commonly associated with addictive tendencies (Pontes \& Griffiths, 2015a; Pontes, Király, Demetrovics, \& Griffiths, 2014; Stubblefield et al., 2017; Wu, Cheung, Ku, \& Hung, 2013).

\section{METHODS}

\section{Participants and procedures}

Potential participants for this study were all students $(N=700)$ enrolled in the sixth, seventh, eighth, and ninth grades of a major middle school located in the Algarve (Portugal). Authorization from the school's principal and parents was obtained, and students completed a survey within the school's library during extracurricular activities. This study was approved by the College Research Ethics Committee of Nottingham Trent University, informed consent was obtained from all individual participants included in the study, and the period of data collection spanned from May to June 2015, and the school was selected on the basis of availability, and the students were randomly sampled from the pool of classes comprising the sixth, seventh, eighth, and ninth grades (i.e., ages 10-18 years) to achieve optimal representativeness of the student population of the participating school. Data were collected from 509 students $(72.7 \%$ of the entire population sampled). The mean age of the sample was 13.02 years $(S D=1.64)$ and there was a relatively equivalent gender split with $53.5 \%(n=265)$ being male (Table 1).

\section{Measures}

Sociodemographics and frequency of technology use. Demographic data were collected on age, gender, and relationship status. Data on SNS usage were collected by asking for participants' average weekly time spent on the Internet for leisure and non-specific (generalized) purposes (i.e., number of hours). Gaming frequency was assessed by asking for participants' average weekly time spent gaming (i.e., number of hours).

The Bergen Facebook Addiction Scale (BFAS). The BFAS (Andreassen, Torsheim, Brunborg, \& Pallesen, 2012) assesses SNS addiction in the context of Facebook use and has been shown to exhibit excellent psychometric properties in a number of countries (Phanasathit, Manwong, Hanprathet, Khumsri, \& Yingyeun, 2015; Salem, Almenaye, \& Andreassen, 2016; Silva et al., 2015), including Portugal (Pontes, Andreassen, \& Griffiths, 2016). The BFAS comprises six items covering the core features of behavioral addictions (i.e., salience, mood modification, tolerance, withdrawal, conflict, and relapse) (Griffiths, 2005). The items are scored on a 5-point scale, i.e., ranging from 1 (very rarely) to 5 (very often) within a time frame of 12 months. Total scores are obtained by totaling up participant ratings of each item (ranging from 6 to 30 points), with higher scores indicating heightened addiction to Facebook. The BFAS has demonstrated adequate levels of reliability in this study $(\alpha=0.83)$.

Internet Gaming Disorder Scale - Short-Form (IGDS9$S F$ ). The IGDS9-SF (Pontes \& Griffiths, 2015a) is a brief psychometric tool designed to assess the severity of IGD over a 12-month period in accordance with framework suggested by the APA in DSM-5 (APA, 2013). The IGDS9-SF has demonstrated adequate psychometric properties and crosscultural validity across a number of countries (Monacis, De Palo, Griffiths, \& Sinatra, 2016; Pontes \& Griffiths, 2015a; Pontes, Macur, et al., 2016), including Portugal (Pontes \& Griffiths, 2016). The nine questions comprising the IGDS9-SF are answered using a 5-point scale, i.e., ranging from 1 (never) to 5 (very often), and scores can be obtained by summing the responses (ranging from 9 to 45 points), with higher scores suggesting a higher degree of GD. The reliability of the IGDS9-SF in this study was satisfactory $(\alpha=0.87)$.

Table 1. Sample's main sociodemographic characteristics, patterns of technology use, levels of addictive use of technology, and psychological health $(N=495)$

\begin{tabular}{lrcc}
\hline Variable & & Minimum & Maximum \\
\hline Age (years) (mean, $S D)$ & $13.02(1.64)$ & 10 & 18 \\
Gender (male, \%) & $265(53.5)$ & - & - \\
In a relationship ( $n, \%)$ & $99(20)$ & - & - \\
Weekly time spent on the Internet (mean, $S D)$ & $17.91(23.34)$ & 1 & 49 \\
Weekly time spent gaming (mean, $S D)$ & $10.21(17.86)$ & 1 & 52 \\
SNS addiction levels (mean, $S D)$ & $10.70(4.83)$ & 6 & 30 \\
IGD levels (mean, $S D)$ & $15.92(6.99)$ & 9 & 41 \\
Depression levels (mean, $S D)$ & $3.12(3.94)$ & 0 & 21 \\
Anxiety levels (mean, $S D)$ & $2.66(3.78)$ & 0 & 21 \\
Stress levels (mean, $S D)$ & $3.32(3.97)$ & 0 & 21 \\
\hline
\end{tabular}

Note. Weekly time spent on the Internet and gaming refer to self-reported number of hours spent on those activities during the week. $S D$ : standard deviation; SNS: social networking site; IGD: Internet gaming disorder. 
Psychological health. Overall psychological health was assessed using the Depression Anxiety and Stress Scales 21 (DASS-21; Lovibond \& Lovibond, 1995), which comprises three 7-item subscales covering the three symptoms that are rated on a 4-point scale, i.e., ranging from 0 (did not apply to me at all) to 3 (applied to me very much or most of the time). The version of the DASS-21 used in this study has been previously shown to possess adequate psychometric properties in the study's population (PaisRibeiro, Honrado, \& Leal, 2004). The Cronbach's $\alpha$ coefficients for this instrument in this study were .84 (depression), .86 (anxiety), and .86 (stress).

\section{Data management and statistical analysis}

Data management involved (i) cleaning the data set by inspecting cases with missing values above the conventional threshold of $10 \%$ in all relevant instruments; (ii) checking for univariate normality of all items of the BFAS and IGDS9-SF using standard guidelines (i.e., skewness > 3 and kurtosis > 9) (Kline, 2011); (iii) screening for univariate outliers that scored \pm 3.29 standard deviations from the BFAS IGDS9-SF $z$-scores (Field, 2013); and (iv) screening for multivariate outliers using Mahalanobis distances and the critical value for each case based on the $\chi^{2}$ distribution values. This procedure resulted in the exclusion of 14 cases, thus yielding a final data set of 495 valid cases that were eligible for subsequent analyses. Statistical analyses included (i) descriptive analysis of the main sample's characteristics, (ii) correlational analysis of the main variables of the study by estimation of Pearson's product-moment correlation coefficients with 95\% bias-corrected and -accelerated (BCa) confidence interval (CI) and accompanying coefficients of determination $\left(R^{2}\right)$, and (iii) a comparative structural equation modeling (SEM) analysis to ascertain the differential predictive role of SNS addiction and IGD on psychological health when accounting for the effects, age, gender, and frequency of Internet use and video game play. Statistical analyses were performed using Mplus 7.2 and IBM SPSS Statistics version 23 (IBM Corporation, 2015; Muthén \& Muthén, 2012).

\section{Ethics}

The study procedures were carried out in accordance with the Declaration of Helsinki. The Institutional Review Board of Nottingham Trent University approved the study. All subjects were informed about the study and all provided informed consent. Moreover, consent from parents and legal guardians was obtained from all participants below 18 years of age.

\section{RESULTS}

\section{Descriptive statistics}

Table 1 summarizes the findings concerning the sample's main sociodemographic characteristics, pattern of technology use, alongside the observed levels of addictive use of technology (i.e., SNS addiction and IGD) and psychological health. Furthermore, both IGD $($ mean $=15.92 \quad[95 \% \quad \mathrm{BCa}=$ $15.31-16.56], S D=6.99)$ and SNS addiction (mean $=$ $10.70[95 \% \mathrm{BCa}=10.28-11.15], S D=4.83$ ) presented with moderate levels within the sample. As for participants' psychological health, depression $($ mean $=3.12 \quad[95 \% \quad \mathrm{BCa}=$ $2.78-3.47], S D=3.94)$, anxiety $($ mean $=2.66[95 \% \mathrm{BCa}=$ $2.33-2.99$ ], $S D=3.78$ ), and stress levels (mean $=3.32[95 \%$ $\mathrm{BCa}=2.98-3.67], S D=3.97)$ were not overly prevalent.

\section{Correlational analysis}

A correlational analysis including the study's main variables was performed to provide preliminary insights and statistical context for the subsequent comparative SEM analysis. As a result, this analysis revealed that SNS addiction was positively associated with $\operatorname{IGD}\left(r=.39, p<.01, R^{2}=.15\right)$, stress $\left(r=.36, p<.01, R^{2}=.13\right)$, and depression $(r=.33, p<.01$, $\left.R^{2}=.11\right)$. With regard to IGD, positive associations emerged with weekly time spent gaming $(r=.42$, $\left.p<.01, R^{2}=.18\right)$, gender $\left(r=.41, p<.01, R^{2}=.17\right)$, and stress $\left(r=.40, p<.01, R^{2}=.16\right)$ (Table 2$)$.

\section{Comparative SEM analysis}

To test the study's main hypotheses, a comparative SEM analysis was performed to estimate the potential differential

Table 2. Bootstrapped ${ }^{\mathrm{a}}$ correlation matrix with bias-corrected and -accelerated (BCa) $95 \%$ confidence interval (CI) between SNS addiction, IGD, and the study variables $(N=495)$

\begin{tabular}{|c|c|c|c|c|c|c|}
\hline Secondary variables & SNS addiction & $R^{2}$ & $95 \% \mathrm{BCa} \mathrm{CI}$ & IGD & $R^{2}$ & $95 \% \mathrm{BCa} \mathrm{CI}$ \\
\hline Age & 0.02 & - & $-0.07-0.10$ & -0.07 & - & $-0.16-0.02$ \\
\hline Gender & 0.04 & - & $-0.05-0.12$ & $0.41^{*}$ & .17 & $0.34-0.48$ \\
\hline Relationship status & $0.20^{*}$ & .04 & $0.11-0.29$ & $0.13 *$ & .02 & $0.03-0.23$ \\
\hline Weekly time spent on the Internet & 0.03 & - & $-0.05-0.12$ & $0.12 *$ & .01 & $0.03-0.22$ \\
\hline Weekly time spent gaming & 0.05 & - & $-0.05-0.14$ & $0.42 *$ & .18 & $0.34-0.50$ \\
\hline Depression & $0.33^{*}$ & .11 & $0.23-0.43$ & $0.36^{*}$ & .13 & $0.26-0.46$ \\
\hline Anxiety & $0.31 *$ & .10 & $0.22-0.41$ & $0.33^{*}$ & .11 & $0.24-0.42$ \\
\hline Stress & $0.36^{*}$ & .13 & $0.25-0.44$ & $0.40^{*}$ & .16 & $0.32-0.49$ \\
\hline IGD & $0.39 *$ & .15 & $0.30-0.48$ & - & - & - \\
\hline
\end{tabular}

Note. SNS: social networking site; IGD: Internet gaming disorder.

${ }^{a}$ Bootstrap results are based on 10,000 bootstrap samples.

*Correlation is significant at 0.01 . 
effects of both SNS addiction and IGD on psychological health. More specifically, a Multiple Indicators, Multiple Causes Model (MIMIC) was tested using maximum likelihood estimation method with robust standard errors. Conventional fit indices and thresholds were adopted to examine the model's goodness of fit: $\chi^{2} / d f[1,4]$, root mean square error of approximation (RMSEA) [0.05, 0.08], RMSEA $90 \%$ CI with its lower limit close to 0 and the upper limit below 0.08 , probability level value of the test of close fit (Cfit) $>.05$, standardized root mean square residual (SRMR) [0.05, 0.08], comparative fit index (CFI), and Tucker-Lewis fit index (TLI) [0.90, 0.95] (Bentler, 1990; Bentler \& Bonnet, 1980; Hooper, Coughlan, \& Mullen, 2008; Hu \& Bentler, 1999). The results of this analysis yielded the following results: $\chi^{2}(722)=1,193.40, \chi^{2} / d f=$ 1.65; RMSEA $=0.036$ [90\% CI: 0.033-0.040], Cfit $=1.00$; $\mathrm{SRMR}=0.049, \mathrm{CFI}=0.92 ; \mathrm{TLI}=0.91$, suggesting that the model presents an optimal fit to the data (Figure 1).

As for the potential role of gender and age in augmenting the symptoms of SNS addiction and IGD (i.e., H1), no support was found for the combined effect of these two variables on SNS addiction. However, gender $(\beta=0.32$, $p<.001)$ and age $(\beta=-0.11, p=.007)$ contributed toward increasing IGD symptoms. More specifically, male gender was associated with greater incidence of IGD symptoms $($ mean $=18.60[95 \% \mathrm{BCa}=4.59-5.97], S D=5.32)$ in comparison with females (mean $=12.83 \quad[95 \% \quad \mathrm{BCa}=$ $6.60-7.70], S D=7.17$ ), and being younger was found to increase overall levels of IGD. On the whole, these findings partially corroborate $\mathrm{H} 1$.

The results from this analysis lend support to $\mathrm{H} 2$ as the standardized effects obtained for the association between SNS addiction and IGD suggested that these two phenomena are positively associated $(r=.53, p<.001)$, a finding that concurs with the results from the correlational analysis with these variables being operationalized as observable measures $(r=.39$ [95\% $\mathrm{BCa}=0.30-0.48], R^{2}=.15$, $p<.01)$ (Table 2).

Finally, the analysis of the differential effects of SNS addiction and IGD on adolescents' psychological health suggested that both technological addictions can have a statistically significant positive effect toward increasing overall levels of psychiatric distress. More specifically, IGD appeared to exacerbate the symptoms of depression $(\beta=0.28, p<.001)$, anxiety $(\beta=0.26, p<.001)$, and stress $(\beta=0.33, p<.001)$. In addition, SNS addiction also contributed toward augmenting the severity of depression $(\beta=0.27, p<.001)$, anxiety $(\beta=0.25, p<.001)$, and stress $(\beta=0.26, p<.001)$, but to a slightly lesser extent. Although these results support $\mathrm{H} 3$, the effects of SNS addiction and IGD on psychological health may not be overly distinct as the standardized effects were highly comparable.

\section{DISCUSSION}

This study sought to investigate the interplay between SNS addiction and IGD and how these two emerging technological addictions can uniquely and distinctively contribute to deterioration of psychological health in adolescents over and above the potential effects stemming from sociodemographic and technology-related variables. With regard to H1 (i.e., gender and age will contribute toward augmenting both SNS addiction and IGD symptoms), this study was able to corroborate this hypothesis in relation to IGD, further supporting a large body of previous studies that found young age and male gender are key variables predicting IGD (Cock et al., 2014; Guillot et al., 2016; Rehbein, Staudt, Hanslmaier, \& Kliem, 2016).

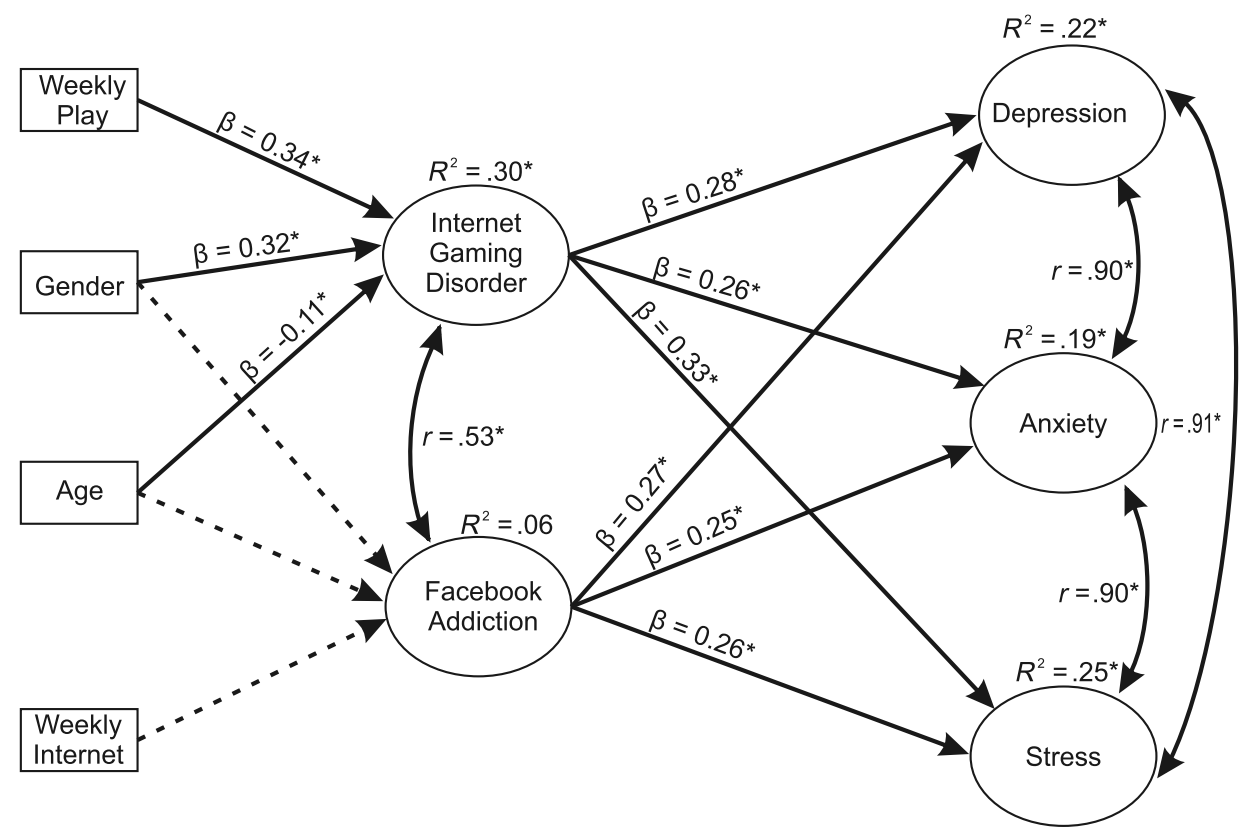

Figure 1. Graphical representation of the differential effects of social networking site addiction and Internet gaming disorders on psychological health $(N=495)$. Note. Overall goodness of fit: $\chi^{2}(722)=1,193.40, \chi^{2} / d f=1.65$; RMSEA $=0.036$ [90\% CI: $\left.0.033-0.040\right]$, Cfit $=1.00 ; \mathrm{SRMR}=0.049, \mathrm{CFI}=0.92 ; \mathrm{TLI}=0.91 . \beta=$ standardized direct effect; $r=$ correlation coefficient. ${ }^{*} p<.0001$ 
Notwithstanding this, H1 was not corroborated in the context of SNS addiction, a finding that adds further complexity to previous studies that reported SNS addiction to be more prevalent among young people (Andreassen et al., 2013, 2012; Turel \& Serenko, 2012), older users (Floros \& Siomos, 2013), females (Andreassen et al., 2012), and males (Çam \& Işbulan, 2012). Nonetheless, the results obtained in this study converge with previous research that found SNS addiction to be unrelated to age (Koc \& Gulyagci, 2013; Wu et al., 2013) and gender (Koc \& Gulyagci, 2013; Tang, Chen, Yang, Chung, \& Lee, 2016; Wu et al., 2013). As previously noted, this might be a result of the poor quality of previous research on SNS addiction in terms of sampling, study design, assessment, and cut-off scores adopted (Andreassen, 2015). Interestingly, weekly time spent on the Internet did not predict increased SNS addiction. A potential explanation for this finding could be related to the fact that online SNS use has become ordinary and inevitable in modern life, making it increasingly difficult for many adolescents to properly estimate their usage, adding further complexity to the relationship between excessive time spent on these technologies and addiction levels. For this reason, it is necessary to acknowledge the difference between high engagement and addiction to SNS as some adolescents spend many hours using SNS as part of a healthy and normal routine (Andreassen, 2015; Andreassen \& Pallesen, 2014; Turel \& Serenko, 2012).

The present findings also lend empirical support to $\mathrm{H} 2$ (i.e., SNS addiction and IGD will be positively associated with each other), validating a number of studies that reported similar results (Andreassen et al., 2013, 2016; Chiu, Hong, \& Chiu, 2013; Dowling \& Brown, 2010). This finding can be explained by the fact that a large number of individuals, including young adolescents now play games through SNS on a regular basis (Griffiths, 2014). Furthermore, it has been long established that the socializing aspects of games play a key motivational role in video game play as suggested by many studies (Demetrovics et al., 2011; Fuster, Chamarro, Carbonell, \& Vallerand, 2014; Yee, 2006). At the clinical level, this finding could point toward shared commonalities underlying these two technological addictions (Griffiths, 2015; Griffiths \& Pontes, 2015; Shaffer et al., 2004). Given that addictive technology use affects individuals in educational settings, research on IGD and SNS addiction among school-based adolescents may help policymakers design preventive policies geared toward mitigating the negative impact of addictive use of technology in young adolescents.

Finally, H3 (i.e., SNS addiction and IGD will both contribute uniquely and differentially toward increasing overall levels of psychiatric distress) was also corroborated and yielded novel insights regarding the combined differential effects of SNS addiction and IGD on adolescents' mental health. In this study, both SNS addiction and IGD contributed toward deterioration of psychological health by increasing levels of depression, anxiety, and stress. This finding supports previous research that has found these two technological addictions to impair mental health independently (Kim, Hughes, Park, Quinn, \& Kong, 2016; Primack et al., 2017; Sampasa-Kanyinga \& Lewis, 2015; Sarda, Bègue, Bry, \& Gentile, 2016). These findings can be utilized by mental health professionals and school counselors wishing to develop intervention programs focused on enhancing the well-being of students by reducing addictive use of technology. Although this finding is promising and worth of future investigation, it is worth noting that evidence regarding the relationship between mental health disorders and behavioral addictions remains inconclusive. More specifically, researchers have reported that behavioral addictions can predict (i.e., primary disorder hypothesis) and be predicted by psychiatric distress (i.e., secondary disorder hypothesis) (e.g., Ostovar et al., 2016; Snodgrass et al., 2014; Zhang, Brook, Leukefeld, \& Brook, 2016). Thus, it is not possible to draw definite conclusions about the directionality regarding behavioral addictions and mental health distress.

Moreover, it was found in this study that the detrimental effects of IGD on psychological health were slightly more pronounced than those produced by SNS addiction. Given the broad deficits exhibited by gamers in several domains of mental health and well-being, this finding is in line with reports suggesting that IGD may reflect a more severe psychopathology in comparison with SNS addiction (Leménager et al., 2016), which partly supports the decision made by the APA (2013) to consider IGD as a tentative disorder. However, additional empirical research using larger and more representative samples would be necessary to further corroborate this hypothesis. In addition to the potential to help shape policies, the present results contribute to the ongoing debates whether technological addictions, such as IGD and SNS addiction, should be conceptualized as primary or secondary disorders. According to the findings reported in this study, conceptualizing technological addictions as primary disorders (i.e., an issue that can negatively affect mental health) is an empirically viable avenue that does not invalidate previous scholarly debates in favor of the view of technological addictions as secondary disorders (i.e., a product of underlying mental health and well-being issues) (Kardefelt-Winther, 2016; Snodgrass et al., 2014; Thorens et al., 2014).

Although the results obtained in this study are empirically sound, there are potential limitations worth noting. First, the data were all self-reported and prone to known biases (e.g., social desirability, memory recall biases, etc.). Second, studies adopting more robust designs (e.g., longitudinal cross-lagged design) would be able to provide more concrete answers to the unique pathways between SNS addiction and IGD and psychological health. Third, because all participants were self-selected, generalization of the present findings to the broad population cannot be directly made. Given the relatively young age of the sample recruited, it is possible that parental control may have had an impact on the self-reported levels of technology use and overall level of addictive use. Thus, future studies assessing technology use in young children and early adolescents should take this variable into account, so better estimates regarding addictive levels can be obtained. Irrespective of these potential limitations, the results of this study extend upon previous research on the interrelationships between technological addictions and their isolated detrimental effects on psychological health by offering an empirically viable framework whereby technological addictions can also increase the likelihood of negative 
psychological health outcomes. In conclusion, the present findings support the conceptualization of technological addictions as primary disorders capable of jeopardizing mental health.

Funding sources: This work was supported by the Portuguese Foundation for Science and Technology (Fundação para a Ciência e Tecnologia) under grant number SFRH/BD/112857/2015. The supporting agency had no role in the design and conduct of the study; collection, management, analysis, and interpretation of the data; and preparation, review, or approval of the article.

Author's contribution: The author of this study was responsible for all stages of this study and he is the sole author of this manuscript.

Conflict of interest: The author declares no conflict of interest.

Acknowledgements: The author of this study would like to thank the participated school, all students, parents, and teachers who have helped organizing the logistics involved in the data collection process of this study.

\section{REFERENCES}

Aarseth, E., Bean, A. M., Boonen, H., Colder, C. M., Coulson, M., Das, D., Deleuze, J., Dunkels, E., Edman, J., Ferguson, C. J., Haagsma, M. C., Helmersson Bergmark, K., Hussain, Z., Jansz, J., Kardefelt-Winther, D., Kutner, L., Markey, P., Nielsen, R. K., Prause, N., Przybylski, A., Quandt, T., Schimmenti, A., Starcevic, V., Stutman, G., Van Looy, J., \& Van Rooij, A. J. (2016). Scholars' open debate paper on the World Health Organization ICD-11 Gaming Disorder proposal. Journal of Behavioral Addictions, 6(3), 267-270. doi:10.1556/2006.5.2016.088

American Psychiatric Association [APA]. (2013). Diagnostic and statistical manual of mental disorders (5th ed.). Arlington, VA: American Psychiatric Association.

Andreassen, C. S. (2015). Online social network site addiction: A comprehensive review. Current Addiction Reports, 2(2), 175-184. doi:10.1007/s40429-015-0056-9

Andreassen, C. S., Billieux, J., Griffiths, M. D., Kuss, D. J., Demetrovics, Z., Mazzoni, E., \& Ståle, P. (2016). The relationship between addictive use of social media and video games and symptoms of psychiatric disorders: A large-scale cross-sectional study. Psychology of Addictive Behaviors, 30(2), 252-262. doi:10.1037/adb0000160

Andreassen, C. S., Griffiths, M. D., Gjertsen, S. R., Krossbakken, E., Kvam, S., \& Pallesen, S. (2013). The relationships between behavioral addictions and the five-factor model of personality. Journal of Behavioral Addictions, 2(2), 90-99. doi:10.1556/ JBA.2.2013.003

Andreassen, C. S., \& Pallesen, S. (2014). Social network site addiction - An overview. Current Pharmaceutical Design, 20(25), 4053-4061. doi:10.2174/13816128113199990616
Andreassen, C. S., Torsheim, T., Brunborg, G. S., \& Pallesen, S. (2012). Development of a Facebook Addiction Scale. Psychological Reports, 110(2), 501-517. doi:10.2466/02.09.18. PR0.110.2.501-517

Bányai, F., Zsila, Á., Király, O., Maraz, A., Elekes, Z., Griffiths, M. D., Andreassen, C. S., \& Demetrovics, Z. (2017). Problematic social media use: Results from a large-scale nationally representative adolescent sample. PLoS One, 12(1), e0169839. doi:10.1371/journal.pone.0169839

Bentler, P. M. (1990). Comparative fit indexes in structural models. Psychological Bulletin, 107(2), 238-246. doi:10.1037/00332909.107.2.238

Bentler, P. M., \& Bonnet, D. G. (1980). Significance tests and goodness of fit in the analysis of covariance structures. Psychological Bulletin, 88(3), 588-606. doi:10.1037/00332909.88.3.588

Bright, L. F., Kleiser, S. B., \& Grau, S. L. (2015). Too much Facebook? An exploratory examination of social media fatigue. Computers in Human Behavior, 44, 148-155. doi:10.1016/j.chb.2014.11.048

Çam, E., \& Işbulan, O. (2012). A new addiction for teacher candidates: Social networks. The Turkish Journal of Educational Technology, 11, 14-19.

Chiu, S.-I., Hong, F.-Y., \& Chiu, S.-L. (2013). An analysis on the correlation and gender difference between college students' Internet addiction and mobile phone addiction in Taiwan. ISRN Addiction, 2013, 1-10. doi:10.1155/2013/360607

Chopik, W. J. (2016). The benefits of social technology use among older adults are mediated by reduced loneliness. Cyberpsychology, Behavior, and Social Networking, 19(9), 551-556. doi:10.1089/cyber.2016.0151

Cock, R. D., Vangeel, J., Klein, A., Minotte, P., Rosas, O., \& Meerkerk, G. (2014). Compulsive use of social networking sites in Belgium: Prevalence, profile, and the role of attitude toward work and school. Cyberpsychology, Behavior, and Social Networking, 17(3), 166-171. doi:10.1089/cyber. 2013.0029

Cole, H., \& Griffiths, M. D. (2007). Social interactions in massively multiplayer online role-playing gamers. CyberPsychology \& Behavior, 10(4), 575-583. doi:10.1089/cpb.2007.9988

Demetrovics, Z., Urbán, R., Nagygyörgy, K., Farkas, J., Zilahy, D., Mervó, B., Reindl, A., Ágoston, C., Kertész, A., \& Harmath, E. (2011). Why do you play? The development of the motives for online gaming questionnaire (MOGQ). Behavior Research Methods, 43(3), 814-825. doi:10.3758/s13428-011-0091-y

Dowling, N. A., \& Brown, M. (2010). Commonalities in the psychological factors associated with problem gambling and Internet dependence. Cyberpsychology, Behavior, and Social Networking, 13(4), 437-441. doi:10.1089/cyber.2009.0317

Facebook. (2014). Facebook@ GDC: Driving discovery and engagement for cross-platform games. Retrieved from https://developers.facebook.com/blog/post/2014/03/19/facebookat-gdc-2014

Field, A. (2013). Discovering statistics using IBM SPSS Statistics (4th ed.). London, UK: Sage Publications Ltd.

Floros, G., \& Siomos, K. (2013). The relationship between optimal parenting, Internet addiction and motives for social networking in adolescence. Psychiatry Research, 209(3), 529534. doi:10.1016/j.psychres.2013.01.010

Fuster, H., Chamarro, A., Carbonell, X., \& Vallerand, R. J. (2014). Relationship between passion and motivation for gaming in 
players of massively multiplayer online role-playing games. Cyberpsychology, Behavior, and Social Networking, 17, 292297. doi:10.1089/cyber.2013.0349

Gentile, D. A., Choo, H., Liau, A., Sim, T., Li, D., Fung, D., \& Khoo, A. (2011). Pathological video game use among youths: A two-year longitudinal study. Pediatrics, 127, e319-e329. doi:10.1542/peds.2010-1353

Griffiths, M. D. (2005). A 'components' model of addiction within a biopsychosocial framework. Journal of Substance Use, 10(4), 191-197. doi:10.1080/14659890500114359

Griffiths, M. D. (2014). Child and adolescent social gaming: What are the issues of concern? Education and Health, 32, 9-12.

Griffiths, M. D. (2015). Classification and treatment of behavioural addictions. Nursing in Practice, 82, 44-46.

Griffiths, M. D., Király, O., Pontes, H. M., \& Demetrovics, Z. (2015). An overview of problematic gaming. In E. Aboujaoude \& V. Starcevic (Eds.), Mental health in the digital age: Grave dangers, great promise (pp. 27-45). Oxford, UK: Oxford University Press.

Griffiths, M. D., Kuss, D. J., \& Pontes, H. M. (2016). A brief overview of Internet gaming disorder and its treatment. Australian Clinical Psychologist, 2, 1-12.

Griffiths, M. D., \& Pontes, H. M. (2015). Addiction and entertainment products. In R. Nakatsu, M. Rauterberg, \& P. Ciancarini (Eds.), Handbook of digital games and entertainment technologies (pp. 1-22). Singapore: Springer.

Griffiths, M. D., Van Rooij, A. J., Kardefelt-Winther, D., Starcevic, V., Király, O., Pallesen, S., Müller, K., Dreier, M., Carras, M., Prause, N., King, D. L., Aboujaoude, E., Kuss, D. J., Pontes, H. M., Fernandez, O. L., Nagygyorgy, K., Achab, S., Billieux, J., Quandt, T., Carbonell, X., Ferguson, C. J., Hoff, R. A., Derevensky, J., Haagsma, M. C., Delfabbro, P., Coulson, M., Hus, Z., \& Demetrovics, Z. (2016). Working towards an international consensus on criteria for assessing Internet gaming disorder: A critical commentary on Petry et al. (2014). Addiction, 111(1), 167-175. doi:10.1111/add.13057

Guillot, C. R., Bello, M. S., Tsai, J. Y., Huh, J., Leventhal, A. M., \& Sussman, S. (2016). Longitudinal associations between anhedonia and Internet-related addictive behaviors in emerging adults. Computers in Human Behavior, 62, 475-479. doi:10.1016/j.chb.2016.04.019

Heo, J., Chun, S., Lee, S., Lee, K. H., \& Kim, J. (2015). Internet use and well-being in older adults. Cyberpsychology, Behavior, and Social Networking, 18(5), 268-272. doi:10.1089/ cyber.2014.0549

Hooper, D., Coughlan, J., \& Mullen, M. R. (2008). Structural equation modelling: Guidelines for determining model fit. Electronic Journal of Business Research Methods, 6, 53-60.

Howard, C. J., Wilding, R., \& Guest, D. (2016). Light video game play is associated with enhanced visual processing of rapid serial visual presentation targets. Perception, 46(2), 161-177. doi: $10.1177 / 0301006616672579$

Hu, L. T., \& Bentler, P. M. (1999). Cutoff criteria for fit indexes in covariance structure analysis: Conventional criteria versus new alternatives. Structural Equation Modeling: A Multidisciplinary Journal, 6(1), 1-55. doi:10.1080/10705519909540118

IBM Corporation. (2015). IBM SPSS statistics for windows, version 23. New York, NY: IBM Corporation.

Kardefelt-Winther, D. (2016). Conceptualizing Internet use disorders: Addiction or coping process? Psychiatry and Clinical Neurosciences, 71(7), 459-466. doi:10.1111/pcn.12413
Kim, N., Hughes, T. L., Park, C. G., Quinn, L., \& Kong, I. D. (2016). Resting-state peripheral catecholamine and anxiety levels in Korean male adolescents with Internet game addiction. Cyberpsychology, Behavior, and Social Networking, 19(3), 202-208. doi:10.1089/cyber.2015.0411

Király, O., Griffiths, M. D., Urbán, R., Farkas, J., Kökönyei, G., Elekes, Z., Tamás, D., \& Demetrovics, Z. (2014). Problematic Internet use and problematic online gaming are not the same: Findings from a large nationally representative adolescent sample. Cyberpsychology, Behavior, and Social Networking, 17(12), 749-754. doi:10.1089/cyber.2014.0475

Kline, R. B. (2011). Principles and practice of structural equation modeling (3rd ed.). New York, NY: Guilford Press.

Koc, M., \& Gulyagci, S. (2013). Facebook addiction among Turkish college students: The role of psychological health, demographic, and usage characteristics. Cyberpsychology, Behavior, and Social Networking, 16(4), 279-284. doi:10. 1089/cyber.2012.0249

Kowert, R., Domahidi, E., Festl, R., \& Quandt, T. (2014). Social gaming, lonely life? The impact of digital game play on adolescents' social circles. Computers in Human Behavior, 36, 385-390. doi:10.1016/j.chb.2014.04.003

Kuss, D. J., Griffiths, M. D., \& Pontes, H. M. (2017). Chaos and confusion in DSM-5 diagnosis of Internet gaming disorder: Issues, concerns, and recommendations for clarity in the field. Journal of Behavioral Addictions, 6(2), 103-109. doi:10.1556/ 2006.5.2016.062

Lee, B. W., \& Stapinski, L. A. (2012). Seeking safety on the Internet: Relationship between social anxiety and problematic Internet use. Journal of Anxiety Disorders, 26(1), 197-205. doi:10.1016/j.janxdis.2011.11.001

Lee, S. Y., Choo, H., \& Lee, H. K. (2017). Balancing between prejudice and fact for gaming disorder: Does the existence of alcohol use disorder stigmatize healthy drinkers or impede scientific research? Journal of Behavioral Addictions, 6(3), 302-305. doi:10.1556/2006.6.2017.047

Lehenbauer-Baum, M., Klaps, A., Kovacovsky, Z., Witzmann, K., Zahlbruckner, R., \& Stetina, B. U. (2015). Addiction and engagement: An explorative study toward classification criteria for Internet gaming disorder. Cyberpsychology, Behavior, and Social Networking, 18(6), 343-349. doi:10.1089/cyber. 2015.0063

Leménager, T., Dieter, J., Hill, H., Hoffmann, S., Reinhard, I., Beutel, M., Vollstädt-Klein, S., Kiefer, F., \& Mann, K. (2016). Exploring the neural basis of avatar identification in pathological Internet gamers and of self-reflection in pathological social network users. Journal of Behavioral Addictions, 5(3), 1-15. doi:10.1556/2006.5.2016.048

Lemmens, J. S., \& Hendriks, S. J. F. (2016). Addictive online games: Examining the relationship between game genres and Internet gaming disorder. Cyberpsychology, Behavior, and Social Networking, 19(4), 270-276. doi:10.1089/cyber. 2015.0415

Lovibond, P. F., \& Lovibond, S. H. (1995). The structure of negative emotional states: Comparison of the Depression Anxiety Stress Scales (DASS) with the Beck Depression and Anxiety Inventories. Behaviour Research and Therapy, 33(3), 335-343. doi:10.1016/0005-7967(94)00075-U

Maraz, A., Király, O., \& Demetrovics, Z. (2015). Commentary on: Are we overpathologizing everyday life? A tenable blueprint for behavioral addiction research. The diagnostic 
pitfalls of surveys: If you score positive on a test of addiction, you still have a good chance not to be addicted. Journal of Behavioral Addictions, 4(3), 151-154. doi:10.1556/ 2006.4.2015.026

Monacis, L., De Palo, V., Griffiths, M. D., \& Sinatra, M. (2016). Validation of the Internet Gaming Disorder Scale - Short-Form (IGDS9-SF) in an Italian-speaking sample. Journal of Behavioral Addictions, 5(4), 683-690. doi:10.1556/2006.5.2016.083

Morioka, H., Itani, O., Osaki, Y., Higuchi, S., Jike, M., Kaneita, Y., Kanda, H., Nakagome, S., \& Ohida, T. (2016). Association between smoking and problematic Internet use among Japanese adolescents: Large-scale nationwide epidemiological study. Cyberpsychology, Behavior, and Social Networking, 19(9), 557-561. doi:10.1089/cyber.2016.0182

Muthén, L. K., \& Muthén, B. O. (2012). Mplus user's guide (7th ed.). Los Angeles, CA: Muthén \& Muthén.

Ostovar, S., Allahyar, N., Aminpoor, H., Moafian, F., Nor, M. B. M., \& Griffiths, M. D. (2016). Internet addiction and its psychosocial risks (depression, anxiety, stress and loneliness) among Iranian adolescents and young adults: A structural equation model in a cross-sectional study. International Journal of Mental Health and Addiction, 14(3), 257-267. doi:10.1007/s11469-015-9628-0

Pais-Ribeiro, J., Honrado, A., \& Leal, I. (2004). Contribuição para o estudo da adaptação portuguesa das Escalas de Ansiedade, Depressão e Stress (EADS) de 21 itens de Lovibond e Lovibond [Contribution to the Portuguese validation study of Lovibond and Lovibond's Short version of the Depression Anxiety and Stress Scale (DASS)]. Psicologia, Saúde \& Doenças, 5, 229-239.

Pantic, I. (2014). Online social networking and mental health. Cyberpsychology, Behavior, and Social Networking, 17(10), 652-657. doi:10.1089/cyber.2014.0070

Pápay, O., Urbán, R., Griffiths, M. D., Nagygyörgy, K., Farkas, J., Kökönyei, G., Felvinczi, K., Oláh, A., Elekes, Z., \& Demetrovics, Z. (2013). Psychometric properties of the problematic online gaming questionnaire short-form and prevalence of problematic online gaming in a national sample of adolescents. Cyberpsychology, Behavior, and Social Networking, 16(5), 340-348. doi:10.1089/cyber.2012.0484

Petry, N. M., Rehbein, F., Gentile, D. A., Lemmens, J. S., Rumpf, H.-J., Mößle, T., Bischof, G., Tao, R., Fung, D. S. S., Borges, G., Auriacombe, M., González-Ibáñez, A., Tam, P., \& O'Brien, C. P. (2014). An international consensus for assessing Internet gaming disorder using the new DSM 5 approach. Addiction, 109(9), 1399-1406. doi:10.1111/add. 12457

Petry, N. M., Rehbein, F., Gentile, D. A., Lemmens, J. S., Rumpf, H.-J., Mößle, T., Bischof, G., Tao, R., Fung, D. S. S., Borges, G., Auriacombe, M., González-Ibáñez, A., Tam, P., \& O'Brien, C. P. (2015). Griffiths et al.'s comments on the international consensus statement of Internet gaming disorder: Furthering consensus or hindering progress? Addiction, 111(1), 175-178. doi:10.1111/add.13189

Phanasathit, M., Manwong, M., Hanprathet, N., Khumsri, J., \& Yingyeun, R. (2015). Validation of the Thai version of Bergen Facebook Addiction Scale (Thai-BFAS). Journal of the Medical Association of Thailand, 98, 108-117.

Pontes, H. M., Andreassen, C. S., \& Griffiths, M. D. (2016). Portuguese validation of the Bergen Facebook Addiction Scale: An empirical study. International Journal of Mental
Health and Addiction, 14(6), 1062-1073. doi:10.1007/s11469016-9694-y

Pontes, H. M., \& Griffiths, M. D. (2015a). Measuring DSM-5 Internet gaming disorder: Development and validation of a short psychometric scale. Computers in Human Behavior, 45, 137-143. doi:10.1016/j.chb.2014.12.006

Pontes, H. M., \& Griffiths, M. D. (2015b). The role of age, age of Internet access initiation, and time spent online in the etiology of Internet addiction. Journal of Behavioral Addictions, 4(Suppl. 1), 30-31. doi:10.1556/JBA.4.2015.Suppl.1

Pontes, H. M., \& Griffiths, M. D. (2016). Portuguese validation of the Internet Gaming Disorder Scale - Short-Form. Cyber psychology, Behavior, and Social Networking, 19(4), 288293. doi:10.1089/cyber.2015.0605

Pontes, H. M., Király, O., Demetrovics, Z., \& Griffiths, M. D. (2014). The conceptualisation and measurement of DSM-5 Internet gaming disorder: The development of the IGD-20 Test. PLoS One, 9(10), e110137. doi:10.1371/journal.pone.0110137

Pontes, H. M., Macur, M., \& Griffiths, M. D. (2016). Internet gaming disorder among Slovenian primary schoolchildren: Findings from a nationally representative sample of adolescents. Journal of Behavioral Addictions, 5(2), 304-310. doi:10.1556/2006.5.2016.042

Primack, B. A., Shensa, A., Escobar-Viera, C. G., Barrett, E. L., Sidani, J. E., Colditz, J. B., \& James, A. E. (2017). Use of multiple social media platforms and symptoms of depression and anxiety: A nationally-representative study among U.S. young adults. Computers in Human Behavior, 69, 1-9. doi:10.1016/j.chb.2016.11.013

Przybylski, A. (2017). Mischievous responding in Internet gaming disorder research. PeerJ, 4, e2401. doi:10.7717/peerj.2401

Rehbein, F., Staudt, A., Hanslmaier, M., \& Kliem, S. (2016). Video game playing in the general adult population of Germany: Can higher gaming time of males be explained by gender specific genre preferences? Computers in Human Behavior, 55(Part B), 729-735. doi:10.1016/j.chb.2015.10.016

Rikkers, W., Lawrence, D., Hafekost, J., \& Zubrick, S. R. (2016). Internet use and electronic gaming by children and adolescents with emotional and behavioural problems in Australia Results from the second Child and Adolescent Survey of Mental Health and Wellbeing. BMC Public Health, 16(1), 399. doi:10.1186/s12889-016-3058-1

Salem, A. A. M. S., Almenaye, N. S., \& Andreassen, C. S. (2016). A psychometric evaluation of Bergen Facebook Addiction Scale (BFAS) of university students. International Journal of Psychology and Behavioral Sciences, 6, 199-205. doi:10. 5923/j.ijpbs.20160605.01

Sampasa-Kanyinga, H., \& Lewis, R. F. (2015). Frequent use of social networking sites is associated with poor psychological functioning among children and adolescents. Cyberpsychology, Behavior, and Social Networking, 18(7), 380-385. doi:10.1089/cyber.2015.0055

Sarda, E., Bègue, L., Bry, C., \& Gentile, D. (2016). Internet gaming disorder and well-being: A scale validation. Cyberpsychology, Behavior, and Social Networking, 19(11), 674679. doi:10.1089/cyber.2016.0286

Saunders, J. B., Hao, W., Long, J., King, D. L., Mann, K., Fauth-Bühler, M., Rumpf, H.-J., Bowden-Jones, H., RahimiMovaghar, A., Chung, T., Chan, E., Bahar, N., Achab, S., Lee, H. K., Potenza, M., Petry, N., Spritzer, D., Ambekar, A., Derevensky, J., Griffiths, M. D., Pontes, H. M., Kuss, D., 
Higuchi, S., Mihara, S., Assangangkornchai, S., Sharma, M., Kashef, A. E., Ip, P., Farrell, M., Scafato, E., Carragher, N., \& Poznyak, V. (2017). Gaming disorder: Its delineation as an important condition for diagnosis, management, and prevention. Journal of Behavioral Addictions, 6(3), 271-279. doi:10.1556/2006.6.2017.039

Scharkow, M., Festl, R., \& Quandt, T. (2014). Longitudinal patterns of problematic computer game use among adolescents and adults - A 2-year panel study. Addiction, 109(11), 19101917. doi:10.1111/add. 12662

Shaffer, H. J., LaPlante, D. A., LaBrie, R. A., Kidman, R. C., Donato, A. N., \& Stanton, M. V. (2004). Toward a syndrome model of addiction: Multiple expressions, common etiology. Harvard Review of Psychiatry, 12(6), 367-374. doi:10.1080/ 10673220490905705

Silva, H. R. S., Areco, K. C. N., Bandiera-Paiva, P., Galvão, P. V. M., Garcia, A. N. M., \& Silveira, D. X. (2015). Equivalência semântica e confiabilidade da versão em português da Bergen Facebook Addiction Scale [Semantic equivalence and confiability of the Portuguese version of the Bergen Facebook Addiction Scale]. Jornal Brasileiro de Psiquiatria, 64(1), 17-23. doi:10.1590/0047-2085000000052

Sioni, S. R., Burleson, M. H., \& Bekerian, D. A. (2017). Internet gaming disorder: Social phobia and identifying with your virtual self. Computers in Human Behavior, 71, 11-15. doi:10.1016/j.chb.2017.01.044

Snodgrass, J. G., Lacy, M. G., Dengah II, H. J. F., Eisenhauer, S., Batchelder, G., \& Cookson, R. J. (2014). A vacation from your mind: Problematic online gaming is a stress response. Computers in Human Behavior, 38, 248-260. doi:10.1016/j. chb.2014.06.004

Starcevic, V., \& Aboujaoude, E. (2016). Internet addiction: Reappraisal of an increasingly inadequate concept. CNS Spectrums, 22(1), 7-13. doi:10.1017/S1092852915000863

Stroud, M. J., \& Whitbourne, S. K. (2015). Casual video games as training tools for attentional processes in everyday life. Cyberpsychology, Behavior, and Social Networking, 18(11), 654-660. doi:10.1089/cyber.2015.0316

Stubblefield, S., Datto, G., Phan, T.-L. T., Werk, L. N., Stackpole, K., Siegel, R., Stratbucker, W., Tucker, J. M., Christison, A. L., Hossain, J., \& Gentile, D. A. (2017). Problem video gaming among children enrolled in tertiary weight management programs. Cyberpsychology, Behavior, and Social Networking, 20(2), 109-116. doi:10.1089/cyber.2016.0386

Sussman, S., Arpawong, T. E., Sun, P., Tsai, J., Rohrbach, L. A., \& Spruijt-Metz, D. (2014). Prevalence and co-occurrence of addictive behaviors among former alternative high school youth. Journal of Behavioral Addictions, 3(1), 33-40. doi:10.1556/JBA.3.2014.005

Tang, J.-H., Chen, M.-C., Yang, C.-Y., Chung, T.-Y., \& Lee, Y.-A. (2016). Personality traits, interpersonal relationships, online social support, and Facebook addiction. Telematics and Informatics, 33(1), 102-108. doi:10.1016/j.tele.2015.06.003

Thorens, G., Achab, S., Billieux, J., Khazaal, Y., Khan, R., Pivin, E., Gupta, V., \& Zullino, D. (2014). Characteristics and treatment response of self-identified problematic Internet users in a behavioral addiction outpatient clinic. Journal of Behavioral Addictions, 3(1), 78-81. doi:10.1556/JBA.3. 2014.008

Turel, O., \& Serenko, A. (2012). The benefits and dangers of enjoyment with social networking websites. European Journal of Information Systems, 21(5), 512-528. doi:10.1057/ejis. 2012.1

Van Rooij, A. J., Schoenmakers, T. M., Vermulst, A. A., Van den Eijnden, R., \& Van de Mheen, D. (2011). Online video game addiction: Identification of addicted adolescent gamers. Addiction, 106(1), 205-212. doi:10.1111/j.1360-0443.2010.03104.x

World Health Organization. (2016). ICD-11 Beta Draft: Gaming disorder. Retrieved from https://icd.who.int/dev11/1-m/en\#/ http\%3a\%2f\%2fid.who.int\%2ficd\%2fentity\%2f1448597234

Wu, A. M. S., Cheung, V. I., Ku, L., \& Hung, E. P. W. (2013). Psychological risk factors of addiction to social networking sites among Chinese smartphone users. Journal of Behavioral Addictions, 2(3), 160-166. doi:10.1556/JBA.2.2013.006

Xanidis, N., \& Brignell, C. M. (2016). The association between the use of social network sites, sleep quality and cognitive function during the day. Computers in Human Behavior, 55(Part A), 121-126. doi:10.1016/j.chb.2015.09.004

Yee, N. (2006). Motivations for play in online games. CyberPsychology \& Behavior, 9(6), 772-775. doi:10.1089/cpb.2006.9.772

Yu, C., Li, X., \& Zhang, W. (2015). Predicting adolescent problematic online game use from teacher autonomy support, basic psychological needs satisfaction, and school engagement: A 2-year longitudinal study. Cyberpsychology, Behavior, and Social Networking, 18(4), 228-233. doi:10.1089/cyber. 2014.0385

Zhang, C., Brook, J. S., Leukefeld, C. G., \& Brook, D. W. (2016). Longitudinal psychosocial factors related to symptoms of Internet addiction among adults in early midlife. Addictive Behaviors, 62, 65-72. doi:10.1016/j.addbeh.2016.06.019 